\title{
Assessing Nonacceptance of the Facial Appearance in Adult Patients After Complete Treatment of Their Rare Facial Cleft
}

\author{
Marijke E. P. van den Elzen • Sarah L. Versnel • \\ Hugo J. Duivenvoorden • Irene M. J. Mathijssen
}

Received: 9 September 2011 / Accepted: 2 March 2012/Published online: 13 April 2012

(C) The Author(s) 2012. This article is published with open access at Springerlink.com

\begin{abstract}
Background Treatment of patients with severe congenital facial disfigurements is aimed at restoring an aesthetic and functional balance. Besides an adequate level of satisfaction, an individual's acceptance of facial appearance is important to achieve because nonacceptance is thought to lead to daily psychological struggles. This study objectified the prevalence of nonacceptance among adult patients treated for their severe facial clefts, evaluated risk factors, and developed a screening tool.

Methods The study included 59 adults with completed treatment for their severe facial cleft. All the patients underwent a semistructured in-depth interview and filled out the Body Cathexis Scale.

Results Nonacceptance of facial appearance was experienced by $44 \%$ of the patients. Of the nonaccepting patients, $72 \%$ experienced difficulties in everyday activities related to their appearance versus $35 \%$ of the accepting patients. Acceptance did not correlate with objective severity or bullying in the past. Risk factors for nonacceptance were high self-perceived visibility, a troublesome puberty period, and an emotion-focused coping strategy. Also, the presence of functional problems was shown to be highly associated.
\end{abstract}

M. E. P. van den Elzen ( $₫)$ · S. L. Versnel · I. M. J. Mathijssen Department of Plastic and Reconstructive Surgery,

Erasmus University Medical Centre, Room Ee 15.91, Dr. Molewaterplein 50, 3015GE Rotterdam, The Netherlands

e-mail: m.vandenelzen@erasmusmc.nl

H. J. Duivenvoorden

Department of Medical Psychology and Psychotherapy, NIHES, Erasmus University Medical Centre, Rotterdam, The Netherlands
Conclusions The objective severity of the residual deformity did not correlate with the patients' acceptance of their facial appearance, but the self-perceived visibility did correlate. The process of nonacceptance resembles the process seen in patients with body dysmorphic disorders. Surgical treatment is no guarantee for an improvement in acceptance and is therefore discouraged for patients who match the risk factors for nonacceptance unless it solves a functional problem. The authors therefore recommend screening patients for nonacceptance and considering psychological treatment before surgery is performed.

Level of Evidence III This journal requires that authors assign a level of evidence to each article. For a full description of these Evidence-Based Medicine ratings, please refer to the Table of Contents or the online Instructions to Authors at www.springer.com/00266.

Keywords Acceptance $\cdot$ Adults $\cdot$ Congenital $\cdot$ Facial disfigurement $\cdot$ Questionnaire $\cdot$ Satisfaction

Patients with severe facial clefts experience multiple operations from a very young age until adulthood. Treatment is aimed at restoring an aesthetic and functional balance. Hopefully, this will lead to a satisfied and selfaccepting patient in the long term, so a "normal life" can be lived. It must be stated that satisfaction and acceptance are not the same: A patient may be dissatisfied with the end result but accept his or her residual deformity.

The abundant number of studies on acceptance covers cohorts of patients with a specific chronic disease or chronic pain $[4-6,9,12,13,15,16,18,20,21,26,27]$. However, reports specifically on acceptance of appearance are scarce $[8,20]$. Within the published studies, acceptance is defined as a willingness to have unwanted experiences 
on some occasions, with reorientation toward positive everyday activities and functioning [16]. Studies concerning patients with chronic diseases or chronic pain have shown that nonacceptance leads to psychological distress and disability, reduced subjective health, depression, anxiety and emotional instability, and avoidance $[5,6,9,14$, 16, 18, 20, 21, 26, 27].

Earlier studies investigating patients with severe congenital facial disfigurement reported that the main problems are on the social functioning level due to prejudices and reactions of disapproval by others $[17,25]$. This results in a fear-avoidance behavior, with patients avoiding confrontations so they will not experience stress $[11,17]$. The model of avoidance behavior is based on a model of exaggerated pain perception of patients with chronic pain who avoid movements and situations so they will not experience pain. Because the reaction of avoidance in patients with chronic pain and facial disfigurement is similar, perhaps the principals of acceptance also may be alike. In view of the fact that amelioration of acceptance in patients with chronic diseases or pain may induce an improved level of psychological wellbeing, less psychological distress, and a higher level of emotional stability [5, 6, 9, 14, 16, 18, 20, 21, 26, 27], this also might be applicable for patients with congenital severe facial disfigurements.

In our opinion, evaluating the satisfaction that patients with severe congenital disfigurement have about their appearance is not enough. A patient's acceptance of his or her facial appearance is of similar clinical importance. Recognizing a patient at risk for nonacceptance is crucial for offering the best treatment to ameliorate acceptance and possibly thereby to enhance psychosocial functioning.

Our first objective was to investigate the prevalence of patients with nonacceptance and to identify risk factors for the development of this nonacceptance. Because most studies investigate the entire group of patients, it can be hard to identify an individual patient. Therefore, the second objective was to construct a short and specific screening tool tailored to test for nonacceptance of an individual patient.

\section{Material and Methods}

\section{Study Population}

Only adult patients with a severe congenital facial deformity were recruited. Of the 123 selected patients with a rare facial cleft (e.g., midline and oblique facial cleft, Treacher Collins syndrome) who had undergone surgery between 1969 and 2009 at the Department of Plastic and Reconstructive Surgery of the Erasmus University Medical Center or Sophia Children's Hospital, Rotterdam, the Netherlands, only 75 were invited to participate in this study. This patient cohort was chosen because they encompassed deformities in all facial units in different sequences [24, 29]. We chose to omit hemifacial microsomia because it represents a relatively large subpopulation and thus would overrepresent a specific type of deformity.

A total of 48 patients were excluded from the study because they met one or more of the following exclusion criteria: deceased $(n=4)$, incomplete data $(n=9)$, age younger than 18 years $(n=32)$, mentally handicapped $(n=1)$, blind $(n=1)$, and insufficient command of the Dutch language $(n=1)$.

\section{Design and Procedure}

A clinical-empirical cross-sectional study was designed and conducted. Ethical approval was received from the board of the Medical Ethical Committee of the Erasmus University Medical Centre Rotterdam (MEC-2006-121).

By mail, patients were sent a cover letter, a patient information form, a questionnaire, and an informed consent form to sign. After the completed questionnaire was returned, an appointment was made for the interview, which was held at the patient's home address.

\section{Questionnaire}

\section{Body Cathexis Scale}

A prior study introduced the modified version of the Body Cathexis Scale (BCS): the Facial BCS. Both the original version [23] and the Facial BCS were used in the current study. The original BCS contains 46 items with a 5-point response scale to measure the function of the body parts and the patient's satisfaction with this function.

The original BCS comprises the whole body, including the face as well, but it does not comprise all the important facial parts and functions. Therefore, in the Facial BCS, extra facial parts and functions were added. A total of five scores were calculated: the original BCS, the Facial BCS, and three subscores (the BCS appearance-of-face, the BCS functionof-face, and the BCS whole-body-without-face. All the scores showed good internal consistency reliability [30]. A validated Dutch version of the original BCS is available [3].

\section{Interview}

The semistructured in-depth interview covered the potential predictive factors chosen and divided into external factors (upbringing, religion, and bullying) and internal factors (coping styles, value of the opinion of others, troublesome puberty, troubles in everyday activities, selfperceived visibility, and whether the patient had the desire 
to undergo psychological treatment). This methodology was chosen to collect data in a qualitative manner because standardized scales might be insensitive to the particular issues of these patients [25].

All the interviews were conducted by a single researcher (SLV). The majority of the questions were open-ended, and responses were followed by a question elaborating on the motives behind the patient's answer. The interview data were assessed using a thematic analysis on the basis of which themes in the qualitative material could be identified by a coding scheme.

\section{Potential Predictive Factors}

\section{Objective Severity of Facial Disfigurement}

Besides the patients' answers in the interview conducted to cover the external and internal potential predictive factors, the severity of the residual facial disfigurement of each patient was independently scored by two experts using the scoring list according to Versnel et al. [31] for facial disfigurement. Recent postoperative standardized photographs of all the patients were used. The average score was calculated in case of different scores.

\section{Measurement of Nonacceptance of Facial Appearance}

The presence of nonacceptance was not queried as a direct question to the patient. It was calculated by answers on multiple questions derived from the interview. The questions concerning nonacceptance were composed by two of the authors In this study, patients were scored as nonaccepting if they encountered true difficulties by looking in a mirror or if they reported not being used to their facial appearance or frequently having psychological struggles due to their appearance with a seriously severe character. The questions in this measurement were chosen because they represent general everyday pursuits unthreatening to answer but very relevant for acceptance. The questions are not about whether the patients like their appearance or not about how much negative impact these unwanted experiences gave them and thus indirectly the willingness to experience them.

\section{Statistical Analyses}

As a measure of central tendency for continuous data, we used mean \pm standard deviation as a measure of dispersion. In case of categorical data, the percentages were calculated. Furthermore, the method of logistic regression analysis was used, with nonacceptance coded as 1 and acceptance as coded as 0 . As a measure of individual performance of the predictor variable, the odds ratio (OR) was estimated, including the corresponding 95\% confidence interval $(95 \% \mathrm{CI})$. All the analyses were adjusted for gender and age. The level of statistical significance was fixed at 0.05 (two-tailed). For statistical analysis, we used the Statistical Package for the Social Sciences (SPSS) for Windows, version 15 (SPSS, Chicago, IL, USA).

\section{Results}

General Characteristics

Of the 75 rare facial cleft patients who met our inclusion criteria, 59 (79 \%) participated in the study. The remaining 16 patients refused for the following reasons: did not respond ( $n=8,4$ lived abroad), found treatment too traumatic $(n=3)$, had interviews with the media about their disfigurement and did not want to talk anymore $(n=2)$, and had emotional difficulties $(n=3)$. The patient characteristics are presented in Tables 1 and 2 .

\section{Prevalence of Nonacceptance}

This study first aimed to objectify the proportion of patients experiencing nonacceptance with their facial appearance (44\% of all the patients). Of the patients experiencing nonacceptance, $72 \%$ reported troubles in everyday activities due to their appearance versus $35 \%$ of accepting patients, which is a significant difference $(p=0.01)$. Also, the patients' desire to undergo psychological treatment was significantly different between the nonaccepting $(48 \%)$ and accepting $(11 \%)$ patients $(p=0.002)$.

Table 1 Patient characteristics

\begin{tabular}{|c|c|}
\hline & $n=59$ \\
\hline \multicolumn{2}{|l|}{ Gender $(\%)$} \\
\hline Male & 32.2 \\
\hline Female & 67.8 \\
\hline \multicolumn{2}{|l|}{ Age (years) } \\
\hline Mean & 34.05 \\
\hline SD & 12.92 \\
\hline Min-Max & $18-74$ \\
\hline \multicolumn{2}{|l|}{ Education level (\%) } \\
\hline Primary school $^{\mathrm{a}}$ & 35.1 \\
\hline High school $^{\mathrm{a}}$ & 47.4 \\
\hline Postgraduation $^{\mathrm{a}}$ & 17.5 \\
\hline \multicolumn{2}{|c|}{ Severity facial deformity } \\
\hline Mean score & 13.90 \\
\hline SD & 7.65 \\
\hline
\end{tabular}


Table 2 Details on patient characteristics

\begin{tabular}{|c|c|c|c|c|c|}
\hline Patient no. & Type of clefts ${ }^{\mathrm{a}}$ & Uni- or bilateral & Total no. of surgeries & OSRFD & Gender \\
\hline 1 & $2,3,4,5,10$ & Bilateral & 16 & 19 & Female \\
\hline 2 & Pure midline $(0-14)$ & & 14 & 4 & Female \\
\hline 3 & Treacher-Collins $(6,7, \& 8)$ & & 1 & 26 & Male \\
\hline 4 & Treacher-Collins $(6,7, \& 8)$ & & 1 & 5 & Female \\
\hline 5 & $2,3,11$ & Unilateral & 18 & 18 & Male \\
\hline 6 & CFND $(0-14+$ craniosynostose $)$ & & 4 & 4 & Female \\
\hline 7 & Pure midline $(0-14)$ & & 4 & 7 & Female \\
\hline 8 & Treacher-Collins $(6,7, \& 8)$ & & 3 & 8 & Female \\
\hline 9 & Treacher-Collins $(6,7, \& 8)$ & & 7 & 19 & Male \\
\hline 10 & Pure midline $(0-14)$ & & 6 & 10 & Female \\
\hline 11 & $0,2,3,4,5,9,11$ & Bilateral & 9 & 26 & Female \\
\hline 12 & ALX3 (0-14) & & 5 & 10 & Female \\
\hline 13 & 4 & Bilateral & 10 & 20 & Male \\
\hline 14 & Treacher-Collins $(6,7, \& 8)$ & & 1 & 1 & Female \\
\hline 15 & $1,2,3$ & Unilateral & 26 & 23 & Male \\
\hline 16 & CFND $(0-14+$ craniosynostose $)$ & & 8 & 20 & Female \\
\hline 17 & Treacher-Collins $(6,7, \& 8)$ & & 2 & 14 & Male \\
\hline 18 & $2,3,7,8,11$ & Bilateral & 7 & 14 & Female \\
\hline 19 & $0,1,2,3,10$ & Bilateral & 14 & 23 & Female \\
\hline 20 & Treacher-Collins $(6,7, \& 8)$ & & 6 & 4 & Male \\
\hline 21 & $0,2,3$ & Unilateral & 3 & 23 & Female \\
\hline 22 & Treacher-Collins $(6,7, \& 8)$ & & 1 & 13 & Male \\
\hline 23 & CFND (0-14 + craniosynostose) & & 7 & 11 & Female \\
\hline 24 & Treacher-Collins $(6,7, \& 8)$ & & 4 & 5 & Female \\
\hline 25 & 3 & Bilateral & 10 & 14 & Male \\
\hline 26 & Pure midline $(0-14)$ & & 9 & 7 & Female \\
\hline 27 & $0,2,3$ & Bilateral & 2 & 6 & Female \\
\hline 28 & 3 & Unilateral & 4 & 12 & Female \\
\hline 29 & Treacher-Collins $(6,7, \& 8)$ & & 3 & 10 & Female \\
\hline 30 & 2,3 & Unilateral & 12 & 9 & Male \\
\hline 31 & Treacher-Collins $(6,7, \& 8)$ & & 3 & 11 & Female \\
\hline 32 & Treacher-Collins $(6,7, \& 8)$ & & 5 & 6 & Female \\
\hline 33 & 2,3 & Unilateral & 11 & 6 & Female \\
\hline 34 & $1,2,3$ & Unilateral & 15 & 7 & Female \\
\hline 35 & 3,4 & Unilateral & 10 & 16 & Female \\
\hline 36 & CFND $(0-14+$ craniosynostose $)$ & & 10 & 19 & Male \\
\hline 37 & 3,4 & Unilateral & 5 & 12 & Female \\
\hline 38 & Treacher-Collins $(6,7, \& 8)$ & & 5 & 10 & Female \\
\hline 39 & CFND $(0-14+$ craniosynostose $)$ & & 2 & 11 & Female \\
\hline 40 & CFND (0-14 + craniosynostose) & & 2 & 10 & Female \\
\hline 41 & ALX3 (0-14) & & 15 & 6 & Female \\
\hline 42 & Treacher-Collins $(6,7, \& 8)$ & & 3 & 4 & Female \\
\hline 43 & 2,3 & Unilateral & 18 & 20 & Male \\
\hline 44 & Treacher-Collins $(6,7, \& 8)$ & & 1 & 16 & Female \\
\hline 45 & 0,3 & Bilateral & 3 & 4 & Male \\
\hline 46 & $0,2,3,4,11$ & Bilateral & 12 & 10 & Male \\
\hline 47 & 3 & Unilateral & 15 & 22 & Female \\
\hline 48 & ALX3 (0-14) & & 15 & 21 & Male \\
\hline
\end{tabular}


Table 2 continued

\begin{tabular}{|c|c|c|c|c|c|}
\hline Patient no. & Type of clefts ${ }^{\mathrm{a}}$ & Uni- or bilateral & Total no. of surgeries & OSRFD & Gender \\
\hline 49 & Treacher-Collins $(6,7, \& 8)$ & & 6 & 17 & Female \\
\hline 50 & CFND (0-14 + craniosynostose) & & 2 & 9 & Female \\
\hline 51 & 2,3 & Unilateral & 16 & 8 & Female \\
\hline 52 & Treacher-Collins $(6,7, \& 8)$ & & 7 & 20 & Male \\
\hline 53 & Treacher-Collins $(6,7, \& 8)$ & & 2 & 14 & Male \\
\hline 54 & 0,2 & Unilateral & 5 & 2 & Female \\
\hline 55 & Treacher-Collins $(6,7, \& 8)$ & & 5 & 11 & Female \\
\hline 56 & $1,2,3,4$ & Unilateral & 11 & 13 & Female \\
\hline 57 & $0,1,2$ & Unilateral & 9 & 15 & Female \\
\hline 58 & Treacher-Collins $(6,7, \& 8)$ & & 3 & 15 & Male \\
\hline 59 & $1,2,3,11$ & Unilateral & 14 & 22 & Male \\
\hline
\end{tabular}

OSRFD Objective Severity of Residual Facial Deformity according to the Versnel scoring list [31]; CFND; ALX

${ }^{a}$ Some patients had multiple clefts simultaneously

\section{Predictive Factors}

The risk factors associated with nonacceptance are presented in Table 3. Because gender was disproportionally represented in this population and age had a significant correlation with nonacceptance $(p=0.04)$, all outcomes were corrected for both age and gender. Educational level was not associated with acceptance and therefore was omitted.

Acceptance was not associated with the external factors such as objective severity of the residual deformity, religious propensity, protective upbringing, and bullying in the past. However, the associated risk factors for nonacceptance were the internal factors of emotional coping strategy, troublesome puberty due to facial appearance, and high self-perceived visibility of the residual deformity. It

Table 3 Association of nonacceptance with potential predictive factors

\begin{tabular}{lllll}
\hline Risk factors & OR & $95 \%$ CI & $p$-value \\
\hline External factors $^{\mathrm{a}}$ & & & & \\
$\quad$ Objective severity & 1.12 & 0.99 & 1.27 & 0.09 \\
$\quad$ Religious propensity & 1.09 & 0.34 & 3.48 & 0.89 \\
Protective upbringing & 0.34 & 0.10 & 1.15 & 0.08 \\
$\quad$ Bullying in past & 0.91 & 0.19 & 4.29 & 0.91 \\
Internal factors & & & & \\
Avoidance coping style & 0.67 & 0.38 & 1.19 & 0.17 \\
Emotional coping style & 3.45 & 1.39 & 8.54 & $\mathbf{0 . 0 1}$ \\
$\quad$ Valuing opinion of others & 1.92 & 0.98 & 3.77 & 0.06 \\
Troublesome puberty & 2.40 & 1.43 & 4.03 & $\mathbf{0 . 0 0}$ \\
Self-perceived visibility & 1.97 & 1.06 & 3.69 & $\mathbf{0 . 0 3}$ \\
\hline
\end{tabular}

$O R$ odds ratio, $C I$ confidence interval

$1=$ nonacceptance; $0=$ acceptance

${ }^{\text {a }}$ All corrected for gender and age

Bold value indicates $\alpha=<0.05$ must be stressed that the external factor of protective upbringing and the internal factors of valuing the opinion of others and an avoidance coping style all had a high OR but an insufficient effect to be significantly different between acceptors and nonacceptors.

Association Between Nonacceptance and Satisfaction with Facial Appearance

Because the BCS is seen as a measurement of satisfaction, the association of the BCS and its subscales with nonacceptance was calculated, as can be seen in Table 4. Nonacceptance was highly associated with all the BCS scores $(p \leq 0.01)$ except the BCS body-without-face score. In addition, the BCS function-of-face was shown to have a remarkably high odds ratio as well (OR, 0.11).

\section{Discussion}

It must be stated that in most cases, even after optimal surgical treatment, total normalization of the facial features

Table 4 Association of Body Cathexis Scale (BCS) with nonacceptance

\begin{tabular}{lllll}
\hline Scale or subscale & OR & \multicolumn{2}{l}{$95 \%$ CI } & $p$-value \\
\hline Original BCS & 0.91 & 0.85 & 0.96 & $\mathbf{0 . 0 0 2}$ \\
Facial BCS & 0.88 & 0.82 & 0.95 & $\mathbf{0 . 0 0 1}$ \\
BCS appearance-of-face & 0.80 & 0.69 & 0.91 & $\mathbf{0 . 0 0 1}$ \\
BCS function-of-face & 0.11 & 0.02 & 0.55 & $\mathbf{0 . 0 0 7}$ \\
BCS whole-body-without-face & 0.90 & 0.77 & 1.06 & 0.20 \\
\hline
\end{tabular}

All corrected for gender and age

$O R$ odds ratio, $C I$ confidence interval

$1=$ nonacceptance; $0=$ acceptance

Bold value indicates $\alpha=<0.05$ 
is seldom achieved, and a patient must face a degree of residue [28, 32]. An earlier study conducted within the same patient population learned that the vast majority of these patients $(83.1 \%)$ were not satisfied with the end result, even when an optimal reconstruction was achieved [30]. At that point, surgical options for improvement were limited. Therefore, acceptance of their own face was important to achieve, especially for the patients dissatisfied with the appearance their face.

The different numbers of patients dissatisfied with facial appearance $(83 \%)$ and those unable to accept it (44\%) clearly illustrate that these are two separate entities for outcome measurement. All the patients who could not accept the appearance of their face also were dissatisfied, whereas only $53 \%$ of the dissatisfied patients could not accept their appearance. The patients with nonacceptance experience this on a daily basis and indicate a greater wish for psychological support.

In this study, the internal predictive factors of high selfperceived visibility of the residual deformity, psychological troubles during puberty, and an emotional coping style were associated with nonacceptance. However, not all the potential predictive factors showed a significant difference between groups of accepting and nonaccepting patients, perhaps due to the relatively small group of patients enrolled in this study. However, looking at the high OR and the clear significant tendency, it is most likely that if our study population had been larger, the factors of protective upbringing, valuing the opinion of others, and an avoidance coping style also would have been differentiating factors between acceptors and nonacceptors. Moreover, the relatively small group also limited the number of risk factors that could be investigated. In addition, the retrospective nature of some questions in the interview might have induced a bias. However, on the other hand, this is how the patient experienced the event in hindsight.

Ideally, a patient at risk for nonacceptance should be identified within a few minutes at the outpatient clinic. Most of the published studies concerning acceptance of appearance are not appropriate for an outpatient clinic setting, particularly due to their length. Finding an individual patient at risk can therefore be difficult.

To tackle this problem, we constructed a screening tool for nonacceptance (Fig. 1) according to questions and predictive factors derived from the interview used in this study. For the reason that this study is only descriptive and

Part I (patient)

1. Do you experience difficulties while looking in a mirror?

2. How difficult is looking in a mirror for you?

3. Are you used to your facial appearance?

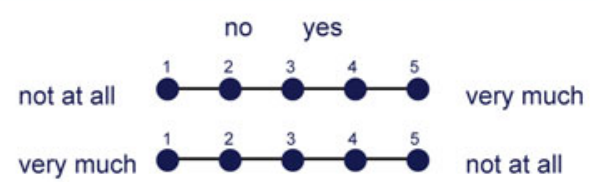

4. a. How often a day do you experience psychological struggles due to your appearance?

b. How often a week do you experience psychological struggles due to your appearance?

c. How often a month do you experience psychological struggles due to your appearance?

d. How often a year do you experience psychological struggles due to your appearance?

5. How severe would you describe your psychological struggles?

very minor

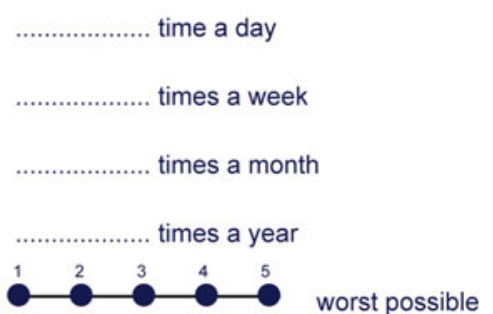

6. How visible do you think your deformity is?

not at all

7. Did you have troubles during puberty due to your deformity?

not at all

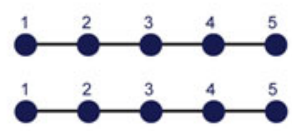

very much

very much

8. If unpleasant things happen to you, how do you react?

Part II (physician)

Calculation of Non-Acceptance: 1. Yes (1point), 2. $\geq 3$ (1 point), 3. $\geq 3$ (1 point), 4. (4.a. $\geq 1$ AND/OR 4.b. $\geq 1$ AND/OR 4.c. $\geq 1$ AND/OR 4.d. $\geq 12$ ) AND 5. $\geq 3$ (1point) Questions 6 and 7 are predictive factors, no calculation in total score. Concerning question 8 , see if reaction is rational (e.g. "tell myself it will be alright") or emotional (e.g. "become sad or agressive, cry" etc.). Total score $\geq 1$ = Non-Acceptor

Fig. 1 Questionnaire for nonacceptance 
explorative toward the screening tool for nonacceptance, further research is necessary to validate and support our screening tool. At this writing, the tool is being tested at the outpatient clinic of the craniofacial team. In addition, this screening tool and the prevalence of nonacceptance must be tested with different types of patients (e.g., reconstructive and aesthetic patients) before the conclusions reached in this study can be extrapolated to other patient groups.

Our results on nonacceptance and its predictive factors imply that amelioration of acceptance with the deformed facial appearance in these patients can be achieved by adjustment to these internal processes and most likely by professional psychological help. The high ratio of patients with a desire for psychological treatment $(48 \%$ ) also reflects this. Studies on acceptance of chronic pain have shown promising results with cognitive behavioral therapy $[10,33]$. Because both the patients with chronic pain and our facially disfigured patients have comparable patterns of fear avoidance and areas of psychological struggles due to their ailment $[11,17]$, the results of psychological treatment might be extrapolated to patients with severe congenital facial disfigurement. In addition, the importance of the upbringing and the troubles experienced during puberty illustrate that acceptance may be established at a young age. Therefore, parents should know about the effect of a protective upbringing and about the standards and values they teach their children. A combined therapy of patients and their parents could therefore be helpful.

Our observation that the objective severity has no association with acceptance suggests that surgery alone might not be the answer to the problems encountered by these patients. However, surgical options to correct residual abnormalities in their faces often are available. Therefore, the question is when to operate on a nonaccepting patient. The answer to this may be found in a different group of patients. The nonaccepting patients in this study were similar in some ways to patients with body dysmorphic disorder (BDD). In short, the definition of BDD is a preoccupation with an imagined or slight physical abnormality that causes significant distress or impairment in social, occupational, or other areas of functioning $[2,22]$. Nonaccepting patients with a residual deformity after completed surgical treatment of their facial cleft have a preoccupation with their deformity, which also leads to social impairment irrespective of the deformity's severity of objective visibility.

In studies of patients with BDD, surgery rarely improves the situation $[1,7,19]$. In contrast, psychological treatment has proved to be more effective in most cases [1]. Surgical treatment for nonaccepting patients with a residual deformity after complete treatment of their facial disfigurement should therefore be reconsidered carefully because their expectations may be unrealistic.
An exception to this recommendation is a surgical procedure to solve functional problems. This study showed that a low score on the BCS function-of-face has a high association with nonacceptance. This implies that the better the function of the face, the more likely will be acceptance of the face. Therefore, a distinction should be made based on the character of the patients' desire for additional surgery. The final recommendation therefore is to withhold surgical interventions for nonaccepting patients with a residual deformity after completed surgical treatment unless the treatment aims at restoring a functional problem.

We conclude that acceptance of one's facial appearance is a different outcome measurement than satisfaction with one's facial appearance and that this difference has high relevance to surgical decision making for the surgeon and also has a serious impact on social functioning for the patient.

Almost half of the adult patients with a rare facial cleft did not accept their facial appearance after completion of surgical treatment. The short questionnaire provided in this study facilitates recognition of these nonacceptors. The objective severity was not correlated with patients' acceptance of their facial appearance, but the self-perceived visibility was correlated with their acceptance. Therefore, it is very unlikely that an additional surgical correction will change the way patients see themselves. Moreover, residual deformities will be visible even after excellent surgical results are achieved. We therefore highlight the option of not operating on these patients who after completing surgical treatment face a residual deformity unless surgery solves a functional problem.

\section{Extrapolation to Other Groups of Patients}

As mentioned earlier, because this study covers a very specific and rare group of patients with severe facial deformities, an extrapolation of these conclusions to other groups of patients cannot be made immediately. The number of patients who experience nonacceptance (44\%) is rather large in this group. To rule out reasons other than the fact that the nonacceptance of these patients just is relatively high, we emphasize that we cannot ascribe this result to a selection bias because all the patients who met our inclusion criteria participated in this study. The 16 patients who did not respond to our invitation to participate in this study were even less courageous, emotionally struggling patients. If they had participated, it is very likely that the number of nonacceptors would have been even higher. Nevertheless, the total number of patients participating in this study was relatively small. Due to the rarity of the facial deformities studied, a larger number was not possible. However, this may have distorted the outcome of this study both by the relatively small number of patients 
and by the very specific group of patients. Also, this observation is made from a single measurement. To determine whether the process of nonacceptance might be dynamic, a longitudinal study would be illustrative.

In conclusion, to validate the described screening tool and to estimate the prevalence of nonacceptance among other types of patient groups, this study must be conducted with other different types of surgical subgroups such as reconstructive and aesthetic patients and with a larger number of patients before the conclusions reached in this study can be extrapolated to other patient groups.

Acknowledgments This study was funded by the CZ Fonds and Stichting Achmea Gezondheidszorg (Dutch Health Insurance Companies). The funding had no role in the design and performance of the study, nor in the collection, management, analysis, or interpretation of the data, nor in the preparation, review, or approval of the manuscript.

Open Access This article is distributed under the terms of the Creative Commons Attribution License which permits any use, distribution, and reproduction in any medium, provided the original author(s) and the source are credited.

\section{References}

1. Anderson RC (2003) Body dysmorphic disorder: recognition and treatment. Plast Surg Nurs 23:125-128 quiz 129

2. AP Association (1994) Diagnostic and statistical manual of mental disorders IV, 4th edn. APA Press, Washington, DC

3. Baardman I, De Jong JG (1984) Het meten van lichaamswaardering. Bewegen en hulpverlening 1:28-41

4. Chao HL, Tsai TY, Livneh $\mathrm{H}$ et al (2010) Patients with colorectal cancer: relationship between demographic and disease characteristics and acceptance of disability. J Adv Nurs 66:2278-2286

5. Evers AW, Kraaimaat FW, van Lankveld W et al (2001) Beyond unfavorable thinking: the illness cognition questionnaire for chronic diseases. J Consult Clin Psychol 69:1026-1036

6. Feldner MT, Zvolensky MJ, Eifert GH et al (2003) Emotional avoidance: an experimental test of individual differences and response suppression using biological challenge. Behav Res Ther 41: 403-411

7. Gorney M (2010) Recognition and management of the patient unsuitable for aesthetic surgery. Plast Reconstr Surg 126: 2268-2271

8. Henderson ER, Pepper AM, Marulanda GA et al (2010) What is the emotional acceptance after limb salvage with an expandable prosthesis? Clin Orthop Relat Res 468:2933-2938

9. Karademas EC, Tsagaraki A, Lambrou N (2009) Illness acceptance, hospitalization stress, and subjective health in a sample of chronic patients admitted to hospital. J Health Psychol 14:1243-1250

10. Lamb SE, Lall R, Hansen $Z$ et al (2010) A multicentred randomised controlled trial of a primary care-based cognitive behavioural programme for low back pain. The Back Skills Training (BeST) trial. Health Technol Assess 14:1-253 iii-iv

11. Lethem J, Slade PD, Troup JD et al (1983) Outline of a FearAvoidance Model of exaggerated pain perception-I. Behav Res Ther 21:401-408

12. McCracken LM (2005) Social context and acceptance of chronic pain: the role of solicitous and punishing responses. Pain 113: $155-159$
13. McCracken LM, Carson JW, Eccleston C et al (2004) Acceptance and change in the context of chronic pain. Pain 109:4-7

14. McCracken LM, Keogh E (2009) Acceptance, mindfulness, and values-based action may counteract fear and avoidance of emotions in chronic pain: an analysis of anxiety sensitivity. J Pain 10:408-415

15. McCracken LM, Velleman SC (2010) Psychological flexibility in adults with chronic pain: a study of acceptance, mindfulness, and values-based action in primary care. Pain 148:141-147

16. McCracken LM, Zhao-O'Brien J (2010) General psychological acceptance and chronic pain: there is more to accept than the pain itself. Eur J Pain 14:170-175

17. Newell RJ (1999) Altered body image: a fear-avoidance model of psychosocial difficulties following disfigurement. J Adv Nurs 30:1230-1238

18. Persson LO, Berglund K, Sahlberg D (1996) A structure of selfconceptions and illness conceptions in rheumatoid arthritis (RA). J Psychosom Res 40:535-549

19. Phillips KA, Grant J, Siniscalchi J et al (2001) Surgical and nonpsychiatric medical treatment of patients with body dysmorphic disorder. Psychosomatics 42:504-510

20. Potocka A, Turczyn-Jablonska K, Merecz D (2009) Psychological correlates of quality of life in dermatology patients: the role of mental health and self-acceptance. Acta Dermatovenerol Alp Panonica Adriat 18:53-58 60, 62

21. Richardson A, Adner N, Nordstrom G (2001) Persons with insulin-dependent diabetes mellitus: acceptance and coping ability. J Adv Nurs 33:758-763

22. Sarwer DB, Crerand CE, Didie ER (2003) Body dysmorphic disorder in cosmetic surgery patients. Facial Plast Surg 19:7-18

23. Secord PF, Jourard SM (1953) The appraisal of body-cathexis: body-cathexis and the self. J Consult Psychol 17:343-347

24. Tessier P (1976) Anatomical classification facial, craniofacial and laterofacial clefts. J Maxillofac Surg 4:69-92

25. Thompson A, Kent G (2001) Adjusting to disfigurement: processes involved in dealing with being visibly different. Clin Psychol Rev 21:663-682

26. Townend E, Tinson D, Kwan J et al (2010) Feeling sad and useless: an investigation into personal acceptance of disability and its association with depression following stroke. Clin Rehabil 24:555-564

27. Van Damme S, Crombez G, Van Houdenhove B et al (2006) Well-being in patients with chronic fatigue syndrome: the role of acceptance. J Psychosom Res 61:595-599

28. van den Elzen ME, Versnel SL, Wolvius EB et al (2011) Longterm results after 40 years experience with treatment of rare facial clefts: Part 2. Symmetrical median clefts. J Plast Reconstr Aesthet Surg 64:1344-1352

29. van der Meulen JC, Mazzola R, Vermey-Keers C et al (1983) A morphogenetic classification of craniofacial malformations. Plast Reconstr Surg 71:560-572

30. Versnel SL, Duivenvoorden HJ, Passchier J et al (2010) Satisfaction with facial appearance and its determinants in adults with severe congenital facial disfigurement: a case-referent study. J Plast Reconstr Aesthet Surg 63:1642-1649

31. Versnel SL, Mulder PG, Hovius SE et al (2007) Measuring surgical outcomes in congenital craniofacial surgery: an objective approach. J Craniofac Surg 18:120-126

32. Versnel SL, van den Elzen ME, Wolvius EB et al (2011) Longterm results after 40 years experience with treatment of rare facial clefts: Part 1. Oblique and paramedian clefts. J Plast Reconstr Aesthet Surg 64:1334-1343

33. Vranceanu AM, Safren S (2010) Cognitive-behavioral therapy for hand and arm pain. J Hand Ther 24:124-130 